\title{
So it goes
}

\section{Gilbert Berdine MD}

The sentence "So it goes" is associated with the author Kurt Vonnegut and his novel SlaughterhouseFive. Every time the narrator of the novel recounts a death, the refrain "So it goes" is appended to the account. The expression has come to be associated with fatalism, stoicism, or both.

The world has become obsessed with COVID-19 statistics. Web sites, including Worldometer, provide daily updates to new cases, total cases, new deaths, and total deaths attributed to COVID-19 for the world, by individual country, and by individual U.S. state. ${ }^{1}$ For example, there were $20,382,294$ cases of COVID-19 in the U.S. during 2020, 32,644,471 cases of COVID-19 during 2021, 373,366 deaths attributed to COVID-19 in the U.S. during 2020 , and 464,413 deaths attributed to COVID-19 during 2021. ${ }^{2}$ So it goes.

If the vaccines are as effective as claimed by authorities, then why did the number of cases of COVID-19 increase following the introduction of the vaccines? If the vaccines are so good at preventing death as claimed by the authorities, then why did the number of deaths attributed to COVID-19 increase in 2021 despite over $60 \%$ of the population receiving full vaccination (which continues to be a moving target)? So it goes. It has become fashionable to blame everything related to COVID-19 on the unvaccinated, but it is difficult to imagine why the unvaccinated would become more susceptible to infection with a higher fatality rate following vaccination of other people. If one tries to drill down through the mortality data, one must step into a Salvador Dali painting in which none of the angles seem quite right (Figure 1).

Figure 2 indicates that U.S. mortality was greater than expected pretty much every day since April 1, 2020. The Centers for Disease Control and Prevention

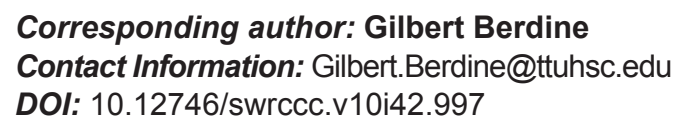

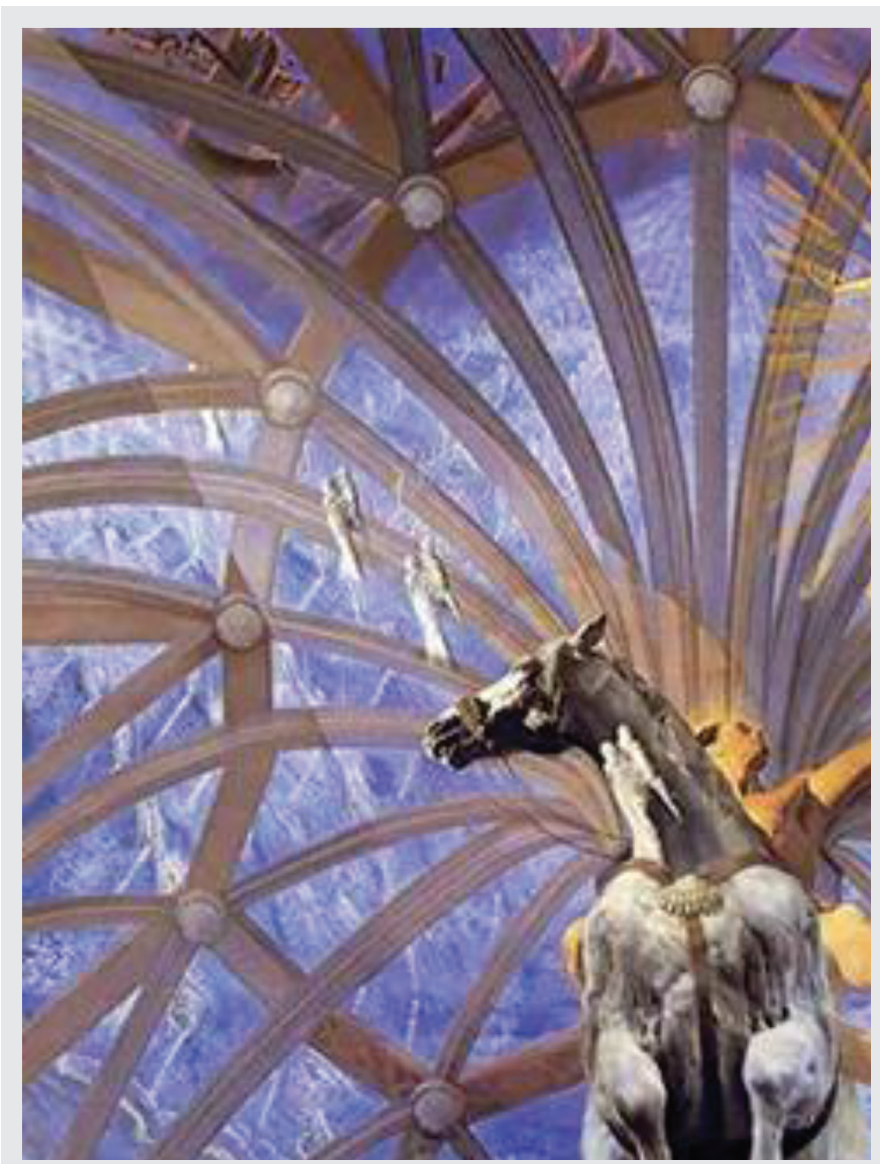

Figure 1. Salvador Dali. Santiago El Grande. 1957. Beaverbrook Art Gallery, Fredericton, New Brunswick, Canada. $^{3}$

(CDC), however, breaks mortality down by cause, and it is difficult to determine the cause that is responsible for the excess deaths. So it goes.

Figure 3 divides the U.S. mortality data by cause of death. The five major categories of cause are Respiratory Diseases, Circulatory Diseases, Malignant Neoplasms, Alzheimer Disease and Dementia, and Other Select Causes. Since COVID-19 is a respiratory infection and death is usually due to advanced ARDS, one would expect excess COVID-19 deaths to 


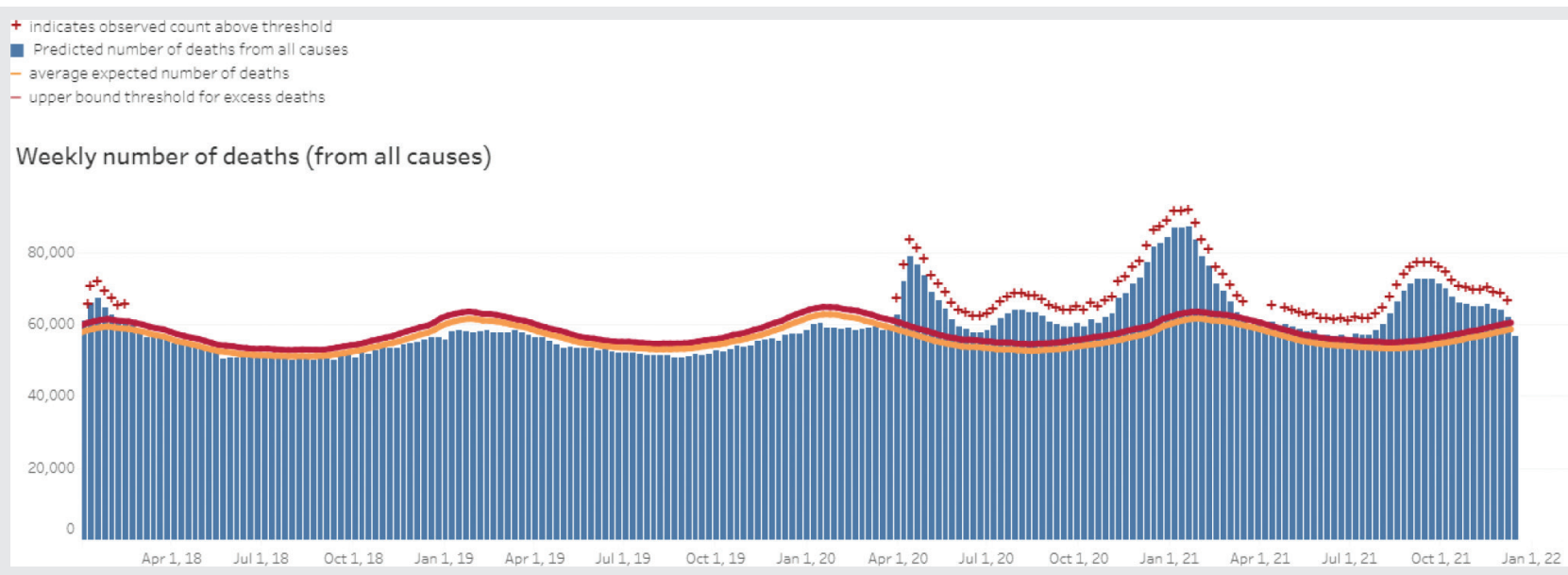

Figure 2. All-cause mortality in United States. Data and figure are from CDC. ${ }^{4}$

show up in the Respiratory Diseases cause subgroup. However, other than during April 2020, death from Respiratory Diseases has not been above average. During the first half of 2021, death from Respiratory Diseases was decidedly below average. Death from Malignant Neoplasms has been at average during both 2020 and 2021. Although death from Alzheimer Disease and Dementia and Death from Other Select Causes have been noticeably above average during 2020 and 2021, neither of these categories appear to have sufficient excess deaths to explain the increase in total excess deaths. So it goes. The only cause category that could possibly explain the excess in total mortality is Circulatory Diseases. It is not immediately clear why COVID deaths would be mislabeled as strokes, myocardial infarctions, or congestive heart failure. So it goes. After looking at the total numbers and the numbers by individual causes, one cannot help wondering whether the CDC keeps two sets of books like an enterprise trying to avoid income taxes.

"A single death is a tragedy; a million deaths is a statistic." This statement has been attributed to Joseph Stalin who was an expert both on death and the political manipulation of statistics. "There are three kinds of lies: lies, damned lies, and statistics." This statement about the political manipulation of statistics has been attributed to British Prime Minister Benjamin Disraeli, $1^{\text {st }}$ Earl of Balfour Arthur James Balfour, and American author Mark Twain. Single deaths can produce martyrs

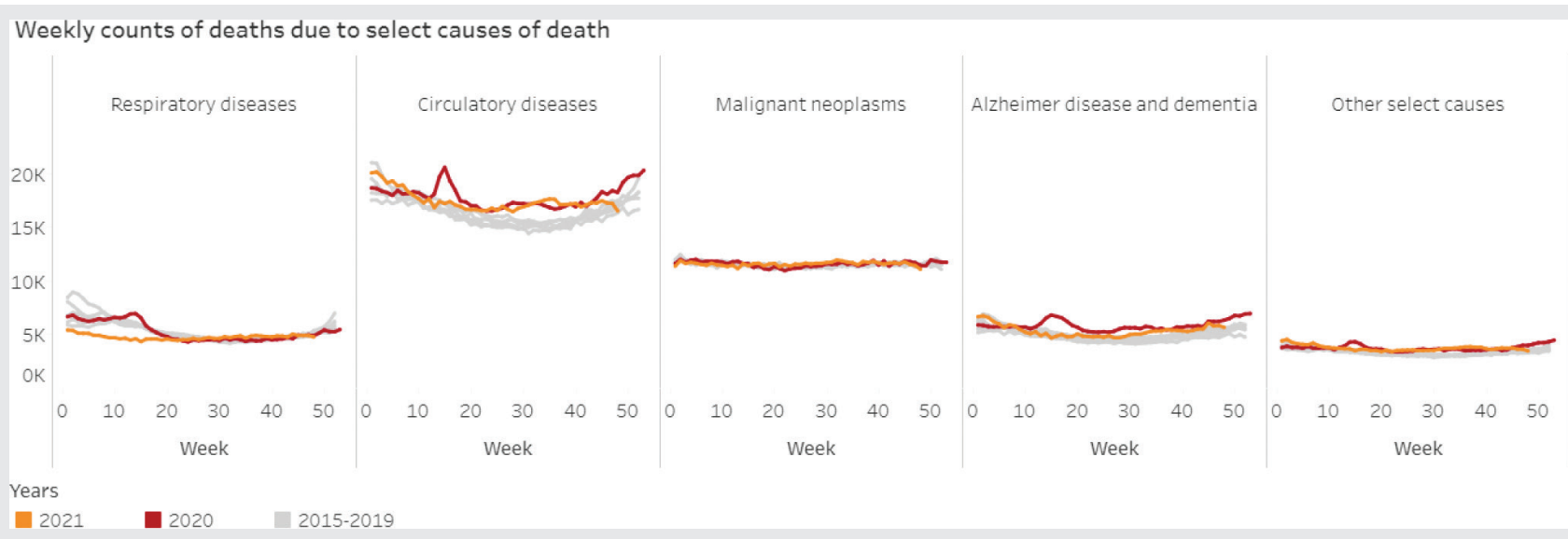

Figure 3. U.S. mortality by cause. Data and figure are from CDC. ${ }^{4}$ 
who inspire large numbers to take a side in conflicts. Capricious and arbitrary executions are instruments of terror to cow people into subservience. Thousands or millions of deaths are shrugged off as collateral damage if the deaths are "enemy" deaths. So it goes.

Politicians often claim credit for successes beyond their control or blame their opponents for failures beyond their control. Examples include the rise and fall of stock markets. The problem of using deaths caused by a virus as a political bludgeon is that it can easily be turned against the newly victorious politician. In a CNN town hall meeting, candidate Joe Biden blamed President Donald Trump for every COVID death, "If the president had done his job, had done his job from the beginning, all the people would still be alive." ${ }^{\circ}$ However, President Joe Biden admits there is no national solution to the even greater number of COVID deaths on his watch. So it goes.

Science is supposed to be objective. Objective facts are necessary to reach correct conclusions and form constructive policies. It has been previously discussed in this journal that it is very difficult to count COVID deaths even in the absence of political motivation. ${ }^{6}$ When science leads to unpleasant conclusions, politicians change definitions or manipulate statistics. However, the physical reality cannot be changed by executive decree or administrative fiat. Political changes to how COVID deaths are counted turn individual human tragedy that can be a unifying force for constructive action into cynical statistics that lead to apathy and rebellion. So it goes.
Keywords: COVID-19 pandemic, mortality

Article citation: Berdine G. So it goes. The Southwest Respiratory and Critical Care Chronicles 2022;10(42):51-53 From: Department of Internal Medicine, Texas Tech University Health Sciences Center, Lubbock, Texas

Submitted: $12 / 26 / 2021$

Accepted: $1 / 7 / 2022$

Conflicts of interest: none

This work is licensed under a Creative Commons Attribution-ShareAlike 4.0 International License.

\section{REFERENCES}

1. COVID Live - Coronavirus Statistics. Worldometer. https:// www.worldometers.info/coronavirus/ Accessed 12/26/2021.

2. United States COVID - Coronavirus Statistics. Worldometer. https://www.worldometers.info/coronavirus/country/us/ Accessed 12/26/2021.

3. Santiago El Grande by Salvador Dali. Salvador Dali Prints. https://salvadordaliprints.org/santiago-el-grande/ Accessed $12 / 26 / 2021$

4. Excess Deaths Associated with COVID-19. Centers for Disease Control and Prevention. https://www.cdc.gov/nchs/nvss/ vsrr/covid19/excess_deaths.htm Accessed 12/26/2021.

5. Joe Biden wrongly claims Trump could've prevented every COVID-19death.https://www.politifact.com/factchecks/2020/ sep/18/joe-biden/joe-biden-wrongly-claims-trump-couldveprevented-e/

6. Cause of death in fatal cases associated with positive COVID19 PCR tests. https://pulmonarychronicles.com/index.php/ pulmonarychronicles/article/view/903/1875 